\title{
Inactivation of spores by nonthermal plasmas
}

\author{
Pradeep Puligundla ${ }^{1} \cdot$ Chulkyoon Mok $^{1} \mathbb{C}$
}

Received: 30 May 2018 / Accepted: 29 August 2018 / Published online: 10 September 2018

(c) Springer Nature B.V. 2018

\begin{abstract}
Bacterial and fungal spore contamination in different industries has a greater economic impact. Because of the remarkable resistance of spores to most physical and chemical microbicidal agents, their inactivation need special attention during sterilization processes. Heat and chemical sporicides are not always well suited for different sterilization/decontamination applications and carries inherent risks. In recent years, novel nonthermal agents including nonthermal plasmas are emerging as effective sporicides against a broad spectrum of bacterial and fungal spores. The present review discusses various aspects related to the inactivation of spores using nonthermal plasmas. Different types of both low pressure plasmas (e.g., capacitively coupled plasma and microwave plasma) and atmospheric pressure plasmas (e.g., dielectric barrier discharges, corona discharges, arc discharges, radio-frequency-driven plasma jet) have been successfully applied to destroy spores of economic significance. Plasma agents contributing to sporicidal activity and their mode of action in inactivation are discussed. In addition, information on factors that affect the sporicidal action of nonthermal plasmas is included.
\end{abstract}

Keywords Inactivation $\cdot$ Nonthermal plasma $\cdot$ Plasma species $\cdot$ Spores $\cdot$ Sterilization

\section{Introduction}

Microbial contamination has significant economic impact in different industries as it leads to product contamination, equipment damage, production downtime, energy losses, and investigations (Eissa et al. 2014). Although vegetative microbial cells are generally most susceptible to inactivation by different microbicidal agents, spores produced by certain bacteria such as Bacillus and Clostridium under unfavorable environmental conditions (e.g., lack of essential nutrients) have been found resistant to high temperatures and toxic chemicals. Owing to their high-level heat resistance, various sterilization processes are designed in such a way as to include the bacterial spores in the inactivating process (Hugo and Russell 1998; Setlow 2013). On the other hand, the existence of fungi or molds, especially mycotoxin and antibiotics producers, in manufacturing environments causes more concern since these types of organisms spread very

Chulkyoon Mok

mokck@gachon.ac.kr

1 Department of Food Science \& Biotechnology, Gachon University, Seongnam-si, Gyeonggi-do 13120, Republic of Korea rapidly by forming spores that are easily transferred from one site to another (Eissa et al. 2014).

Bacterial spores are highly resistant to physical and chemical agents (Gould 1983; Russell 1990; Setlow 2006, 2013; Waites 1985). They can endure various disinfection treatments and sterilization processes (Leggett et al. 2012). This is of great concern in food processing and biomedical industries as they involve in the persistence of contamination (Stapelmann et al. 2013). Bacillus subtilis spores are commonly used as test organisms to study the effects of sporicidal treatments owing to their greater degree of resistance to different physicochemical treatments, their genetic traceability and non-pathogenicity, and their reproducible inactivation response (Humphreys 2011; Nicholson et al. 2000; Nicholson and Galeano 2003; Setlow 2006). In the food industry, spore-forming thermophilic Alicyclobacillus spp. have been recognized as significant spoilage organisms in beverages (Friedrich et al. 2009; Matsubara et al. 2002; Merle and Montville 2014), and endospore-forming Clostridium perfringens is a causative of histotoxic and gastrointestinal (GI) diseases in humans and animals (Akhtara et al. 2009; McClane 2001; Songer 1996).

Chemical sporicides are virtually considered sterilants because they can destroy all types of organisms, including bacterial spores. The important chemical sporicides include 
formaldehyde (liquid and vapor forms), glutaraldehyde, chlorine releasing agents, ethylene oxide and peroxygens (Russell 1990). However, several types of sporicidal agents are extremely corrosive to stainless steel, plastic, and soft metals and can contribute to health hazards to operators. Certain low toxicity sporicidal agents such as hydrogen peroxide $\left(\mathrm{H}_{2} \mathrm{O}_{2}\right)$ have been suggested for antimicrobial treatment of irritable goods, which come into close contact with living tissue but cannot be sterilized by conventional methods (von Woedtke et al. 2004).

Conventional high-temperature, long-time heat processing can sufficiently inactivates spores (even spores of $B$. subtilis) in foods, but negatively impacts their quality. However, advanced techniques such as the use of radio-frequency flash heating (RF-FH) was shown to improve product quality, while still maintaining effective spore inactivation (Uemura et al. 2010). On the other hand, nonthermal methods of spore inactivation are gaining popularity in recent years owing to their suitability for heat-sensitive materials and against heat-resistant spores. Nonthermal, non-chemical sterilizing agents such as UV and gamma radiation were shown to be effective against the spores of Bacillus species (Silva et al. 2013). In a study, a UV-C radiation (200-280 nm) dose of $23.72 \mathrm{~J} / \mathrm{mL}$ has been shown to reduce the spores of Bacillus coagulans, Bacillus cereus, Alicyclobacillus acidocaldarius, Bacillus licheniformis, and Geobacillus stearothermophilus by $2.25,2.93,3.24,3.85$, and $4.05 \log _{10}$ units, respectively (Gayán et al. 2013). As a nonthermal technique, ultrasound treatment singly and in combination with surfactants was found to be effective than conventional sanitizers containing chlorine for reducing numbers of $B$. cereus spores on iceberg lettuce (Sagong et al. 2013). In recent years, nonthermal plasma is regarded as a potential alternative to conventional spore sterilization agents. Spore inactivation using nonthermal plasma is a novel, cost-effective, and environmentally friendly technique compared to conventional autoclave and chemical treatments (Huang 2011).

\section{Nonthermal plasma}

Plasma is an ionized gas or partially ionized gas containing an equal number of positive and negative charges, and some nonionized gas particles. Plasmas can be categorized basically into two types, high temperature and low temperature plasmas, based on the relative energetic levels of electrons and heavy particles of plasma (Asenjo-Castillo and VargasBlanco 2016). In high temperature plasma, all the species of plasma, including ions, electrons, and neutral molecules, are in thermal equilibrium state $\left(T_{e} \approx T_{i} \approx T_{g}, T_{p}=10^{6}-10^{8} \mathrm{~K}\right)$. Where, $T_{e}=$ electron temperature, $T_{i}=$ ion temperature, $T_{g}=$ gas temperature. On the other hand, low temperature plasmas are subdivided into thermal plasma (or quasi-equilibrium plasma), which is in a local thermal equilibrium
(LTE) state $\left(T_{e} \approx T_{i} \approx T_{g} \leq 2 \times 10^{4} \mathrm{~K}\right)$, and nonthermal plasma (NTP) (or non-equilibrium plasma or cold plasma), which can be generated if most of the coupled energy is transmitted into the electrons and only their temperature reaches the high values $\left(T_{e} \gg T_{i} \approx T_{g} \leq 300 \ldots 10^{3} \mathrm{~K}\right)$ (Nehra et al. 2008; Scholtz et al. 2015). NTP can be generated by electrical discharges in gases under either low $\left(10^{-4}-10^{-2} \mathrm{kPa}\right)$ or atmospheric pressure. Atmospheric pressure NTPs consist of various active agents, namely particles as neutral or excited atoms and molecules, negative and positive ions, free radicals and free electrons, and UV photons. The common electrical discharges such as corona discharge, dielectric barrier discharge, microwave discharge, and plasma jet are used to generate nonthermal plasma. A detailed description regarding atmospheric pressure plasmas can be found in a review paper by Tendero et al. (2006). In addition, introductory literature on plasma generation, physics and engineering aspects can be obtained from book by Fridman and Kennedy (2004) and from a book by Laroussi et al. (2012).

\section{Sporicidal activity of nonthermal plasmas}

Although several studies have demonstrated the effectiveness of nonthermal plasmas against bacteria and fungi or yeast in their vegetative states, there are a limited number of studies on their potentiality for spore inactivation. The use of gas plasma as a sterilizing agent was first patented by Menashi (1968). He concluded that the sterilization of vials containing $10^{6}$ spores can be achieved in $<1 \mathrm{~s}$ by using an argon plasma generated by a pulsed RF field at atmospheric pressure. Further studies by Ashman and Menashi (1972), Boucher (1980), and Bithell (1982) showed that an electrical discharge in an appropriate gas (or gases) could lead to sterilization (Thiyagarajan 2004). To increase the efficacy of sterilizing process, halogens (chlorine, bromine and iodine) instead of inert gases (argon or helium) were added within the sterilization chamber by Ashman and Menashi (1972). In inactivating bacterial spores, some gases (e.g. $\mathrm{CO}_{2}$ ) were found more efficient than others (e.g. argon) (Boucher 1985). However, Ratner et al. (1990) showed that, irrespective of the type of discharge, sterilization is efficient with most discharge gases $\left(\mathrm{O}_{2}, \mathrm{~N}_{2}\right.$, air, $\mathrm{H}_{2}$, halogens, $\mathrm{N}_{2} \mathrm{O}, \mathrm{H}_{2} \mathrm{O}, \mathrm{H}_{2} \mathrm{O}_{2}$, $\mathrm{CO}_{2}, \mathrm{SO}_{2}, \mathrm{SF}_{6}$, aldehydes).

\section{Low-pressure plasmas}

In a study by Stapelmann et al. (2013), low-pressure plasmas were used to inactivate wild-type spores of Bacillus pumilus SAFR-032 and B. subtilis 168 on the surface of stainless steel screws. The spore-contaminated (artificially) screw samples were exposed to the plasmas, which were generated with $\mathrm{H}_{2}$ and/or with $\mathrm{O}_{2}$ and evaporated $\mathrm{H}_{2} \mathrm{O}_{2}$ as a process 
gas, at a pressure range of 5-25 $\mathrm{Pa}$ and at power 100 and $400 \mathrm{~W}$, in a very high frequency capacitively coupled plasma reactor. The spores of the B. pumilus SAFR-032 exhibited more resistance against the plasmas compared to the spores of the B. subtilis 168 . In addition, an enhanced inactivation of the test spores was noted upon the use of the low-pressure plasmas with an additional treatment using $\mathrm{H}_{2} \mathrm{O}_{2}$. These results indicate the plasma potentiality to reduce spore contamination, especially in spacecraft hardware components.

Moreau et al. (2000) investigated the sporicidal activity of the flowing afterglow of a microwave discharge against B. subtilis spores. A complete inactivation of $10^{6} \mathrm{~B}$. subtilis spores was achieved within 40 min of exposure to the afterglows of microwave discharges, which were generated using $5 \% \mathrm{O}_{2} / \mathrm{Ar}$ and $5 \% \mathrm{O}_{2} / \mathrm{N}_{2}$ mixtures, with $100 \mathrm{~W}$ absorbed microwave power, at pressure 7 Torr and gas flow rate of $2000 \mathrm{sccm}$ (standard cubic centimeter per minute) and at afterglow gas temperatures not exceeding $50{ }^{\circ} \mathrm{C}$.

Microwave plasmas generated using different plasma gas compositions $\left(\mathrm{O}_{2}, \mathrm{O}_{2} / \mathrm{Ar}, \mathrm{O}_{2} / \mathrm{H}_{2}, \mathrm{CO}_{2}\right.$, and $\left.\mathrm{O}_{2} / \mathrm{CF}_{4}\right)$ exhibited varied $B$. subtilis spore inactivation levels. The $\mathrm{O}_{2} / \mathrm{CF}_{4}$ lowtemperature gas plasma was shown to inactivate the spores in excess of $>5 \log$ in $7.5 \mathrm{~min}$ when compared with other plasma gas compositions (a 2 log decrease was noted with pure $\mathrm{O}_{2}$ ) (Lerouge et al. 2000a).

A proportional relationship between microwave power density of an Ar plasma and the inactivation of spores (used as bio-indicators) has been shown by Purevdorj et al. (2001). In that study, Under a low gas pressure of $50 \mathrm{~Pa}$, microwave-induced Ar plasmas were generated at microwave power densities of $1.47,2.63$ and $4.21 \mathrm{~W} \mathrm{~cm}^{-3}$, at an ambient temperature of $15^{\circ} \mathrm{C}$ to obtain low temperature distribution of 31,35 and $43^{\circ} \mathrm{C}$, respectively. Among the three types of spores tested (B. subtilis, Bacillus stearothermophilus and B. pumilus), the B. subtilis exhibited maximum Ar plasma resistance, whereas the B. stearothermophilus exhibited minimum resistance. Upon exposure of the B. pumilus, which exhibited moderate Ar plasma sensitivity, to the Ar plasma generated at $2.63 \mathrm{w} \mathrm{cm}^{-3}$ microwave power density, 1.67-1.95 log $(\mathrm{No} / \mathrm{N})$ degree of inactivation was observed irrespective of initial spore density in the range of $\times 10^{4}-\times 10^{8}$.

Sporicidal potential of low pressure oxygen-based plasmas has been tested against Bacillus spores (Hury et al. 1998). In this study, the spores of four Bacillus species, namely B. subtilis, B. pumilus, B. cereus and B. stearothermophilus, were used. In the plasma generation process, into a DECR (distributed electron cyclotron resonance) plasma reactor, gases $\left(\mathrm{Ar}, \mathrm{O}_{2}, \mathrm{CO}_{2}\right)$ or vapors $\left(\mathrm{H}_{2} \mathrm{O}_{2}, \mathrm{H}_{2} \mathrm{O}\right)$ were introduced at 4 millitorr operating pressure, and the plasma was excited with a microwave power of $600 \mathrm{~W}$. The $\mathrm{O}_{2}$, $\mathrm{H}_{2} \mathrm{O}_{2}$ and $\mathrm{CO}_{2}$ plasmas exhibited much long-term effects than the Ar plasma, but both the $\mathrm{H}_{2} \mathrm{O}_{2}$ and $\mathrm{CO}_{2}$ plasmas exhibited a higher destruction efficiency than the $\mathrm{O}_{2}$ plasma. A 6-log unit reduction was observed upon the $\mathrm{CO}_{2}$ plasma treatment for $30 \mathrm{~min}$ with a treatment temperature of $60{ }^{\circ} \mathrm{C}$. Some additional studies on spore inactivation by low pressure plasmas, especially using microwave-powered cold plasmas, are given in Table 1.

\section{Atmospheric pressure plasmas}

Dielectric barrier discharges (DBDs) were investigated for packaging sterilization (Trompeter et al. 2002). In this study, B. subtilis and Aspergillus niger spores were reduced by DBDs generating using different gas mixtures and plasma conditions. Among different gases or mixtures of gases used (Ar, synthetic dry and moistened air, a mixture of $\mathrm{O}_{2}$ and $\mathrm{O}_{3}$ and $\mathrm{N}_{2}$ and $\mathrm{N}_{2}$ with $1 \%$ added $\mathrm{H}_{2}$ ), argon discharge was found to be the most efficient gas in terms of spore inactivation. Heise et al. (2004a) investigated the sterilization efficiency of different DBD setups against spores of $B$. subtilis and A. niger sprayed onto PET foils. A single-gap DBD in argon gas showed the fastest and highest efficiency of reduction of both spore types compared with DBDs generated in other gases, namely nitrogen and synthetic air. However, a cascaded DBD (CDBD), which combines UV light and reactive plasma, was found to be more efficient compared with normal DBDs for spore inactivation, even for UV-resistant cells (Heise et al. 2004a). The CDBD was obtained by introducing a second dielectric into the gap of a normal barrier discharge configuration (Heise et al. 2004b). The flowing afterglow of a DBD in air was used to inactivate spores of Bacillus genus (Laroussi and Leipold 2004). The sporicidal effect of an atmospheric pressure glow (APG) or DBD, which was excited at two frequency ranges: audio-frequency range $(100 \mathrm{kHz}, 80 \mathrm{~W})$ and radio-frequency range (13.56 MHz, 150-200 W), has been tested against B. atrophaeus $\left(2.0 \times 10^{6} \mathrm{CFU}\right)$ and $G$. stearothermophilus $\left(1.3 \times 10^{6} \mathrm{CFU}\right)$ (Akitsu et al. 2005). In that study, a complete sterilization of the spores was reported after treatment using the APG at $100 \mathrm{kHz}$ for $30 \mathrm{~min}$; and the sterilization of spores of G. stearothermophilus applied on stainlesssteel carrier covered by Tyvek package was achieved after treatment using the APG plasma at $13.56 \mathrm{MHz}$ for $5 \mathrm{~min}$. The sporicidal activity of a sheet-type DBD was tested using spores of G. stearothermophilus (Eto et al. 2008). In this study, DBD generated in actual air (humidity 64.4\%) inactivated the spore population of $10^{6}$ in $4.5 \mathrm{~min}$ at a temperature of $28.4^{\circ} \mathrm{C}$. The obtained results confirmed the potentiality of DBD plasma for low-temperature sterilization of medical instruments wrapped with Tyvek packaging.

Bacillus cereus and Bacillus anthracis spores treated using DBD plasma (at a discharge power of $0.3 \mathrm{~W} \mathrm{~cm}^{-2}$ ) in liquid or air-dried on a solid surface were effectively inactivated within $1 \mathrm{~min}$. In addition, up to $7 \log$ reduction in 


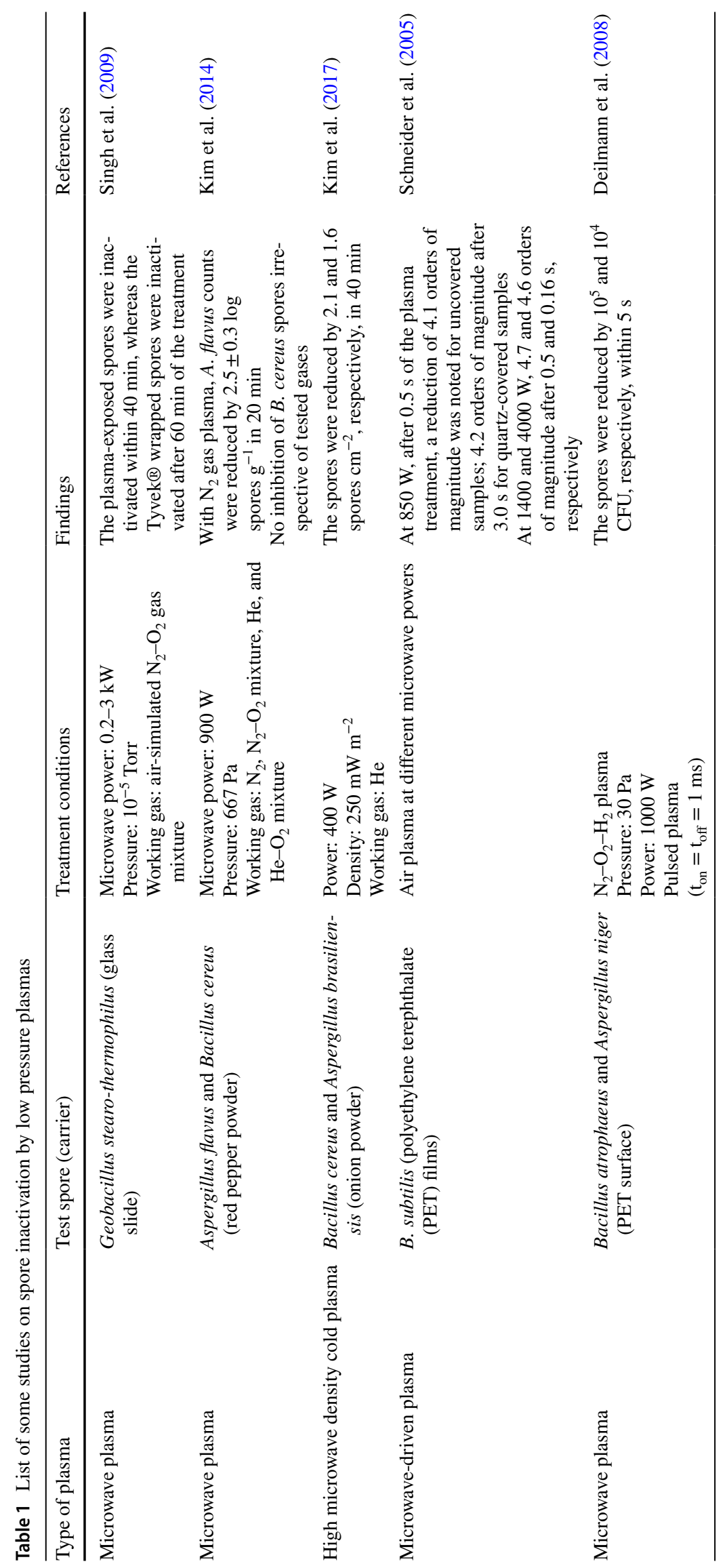


the viability of air-dried spores was observed by the DBD plasma treatment for $45 \mathrm{~s}$ (Dobrynin et al. 2010). In another study, direct exposure of a DBD high voltage atmospheric cold plasma (HVACP) generated between two aluminum plate electrodes for $60 \mathrm{~s}$ resulted in $\geq 6 \log _{10}$ cycle reduction of B. atrophaeus spores (initial spore population 6.36 $\log _{10} /$ strip) inside a sealed package in all gas types, namely atmospheric air (gas type 1), $90 \% \mathrm{~N}_{2} \pm 10 \% \mathrm{O}_{2}$ (gas type 2), and $65 \% \mathrm{O}_{2} \pm 30 \% \mathrm{CO}_{2} \pm 5 \% \mathrm{~N}_{2}$ (gas type 3), tested (Patil et al. 2014). On the other hand, indirect exposure for $60 \mathrm{~s}$ resulted in either 2.1 or $6.3 \log _{10}$ cycle reduction of the spores depending on gas types used for HVACP generation. Finally, the results showed that direct and indirect HVACP exposure for $60 \mathrm{~s}$ at $70 \%$ relative humidity $(\mathrm{RH})$ resulted in 6.3 and $5.7 \log _{10}$ cycle reduction of the spores, respectively (Patil et al. 2014). These studies confirmed that humidity plays a greater role in spores' inactivation irrespective of plasma type. A quick sterilization method for dry and wet samples of $B$. subtilis spores by DBD plasma was shown recently by Mizuno (2017). The spore sample with $10^{6}$ $\mathrm{CFU} / 100 \mu \mathrm{L}$ density was applied on an aluminum plate and dried (the dry sample) or to an agarose gel for the wet sample. An AC voltage of $20 \mathrm{kVp}$-p, and $2 \mathrm{kHz}$ was used with a power density of the plasma of $1.2 \mathrm{~W} \mathrm{~cm}^{-2}$. On treatment with the plasma, the viability of dry sample was reduced to $<10^{-6}$ within $10 \mathrm{~s}$. Under the wet condition, sterilization is dependent on $\mathrm{pH}$ value of the sample. The survival rate decreased to $10^{-6}$ in $20 \mathrm{~s}$ upon quick decrease of the gel $\mathrm{pH}$ value (acidic). And, it was taken about $60 \mathrm{~s}$ to decrease the survival rate to $10^{-6}$ at a constantly maintained $\mathrm{pH}$ 7.0.

The antimicrobial effect of two different atmospheric pressure plasmas, direct plasma treatment with a radio frequency (rf) plasma jet and remote treatment with a microwave generated plasma, for the decontamination of whole black pepper was investigated (Hertwig et al. 2015). Using either of these two types of plasma, naturally contaminated peppercorns and peppercorns inoculated with $B$. subtilis spores, B. atrophaeus spores and Salmonella enterica (approx. $10^{7} \mathrm{CFU} \mathrm{g}{ }^{-1}$ ) were treated. The peppercorns were found to be naturally contaminated (predominantly) with aerobic endospores (average of $7.7 \mathrm{log}$ ) and presumptive B. cereus spores (average of $7.7 \mathrm{log}$ ). After $30 \mathrm{~min}$ of the remote plasma treatment, the $S$. enterica, $B$. subtilis spores and $B$. atrophaeus spores were reduced by $4.1,2.4$ and $2.8 \mathrm{log}$, respectively; whereas, a reduction of $1.7 \mathrm{log}$ was observed for the total spore count (natural contaminants) following the 30-min treatment. An equivalent inactivation levels were not observed with direct plasma jet treatment. However, both types of plasma applications did not affect the pepper quality considerably (Hertwig et al. 2015).

The sporicidal effect of an atmospheric pressure microwave-induced argon plasma against $B$. subtilis spores was shown by Park et al. (2003). In this study, an initial count of $10^{7}$ spores were sterilized in $20 \mathrm{~s}$, Whereas spores of fungus Penicillium citrinum were deactivated relatively quickly (10 s of the plasma exposure). In another study, they used the microwave-induced argon plasma as a potential tool for sterilization of paper materials contaminated with fungi. The suspensions of fungal (Aspergillus niger, Cladosporium cladosporiodes, Penicillium citrinum, and Chaetomium sp.) spores (approx. 100,000-500,000 CFU mL ${ }^{-1}$ ) were inoculated onto sterile filter papers in Petri dishes. Following the plasma treatment, spores of all the fungi on the filter papers were inactivated in $<1 \mathrm{~s}$ (Park et al. 2004).

A high-density nonequilibrium atmospheric pressure plasma (NEAPP) was employed for inactivating fungal spores of Penicillium digitatum, a difficult-to-inactivate food spoilage microorganism (Iseki et al. 2010). The electron density of the NEAPP generated using Ar gas was $10^{15} \mathrm{~cm}^{-3}$. The spores rapidly inactivated using the NEAPP, with a decimal reduction time in spores (D value) of $1.7 \mathrm{~min}$.

Keener et al. (2012) evaluated PK-1 (a system capable of generating ozone inside a sealed package; it was operated at $44 \mathrm{~W}, 13.5 \mathrm{kV}$ potential between the electrodes with $1.0 \mathrm{~cm}$ gap) and PK-2 $(80 \mathrm{kV} / 150 \mathrm{~W} / 4.5 \mathrm{~cm})$ systems, which were based on the principles of nonthermal, atmospheric plasma, in the reduction of $B$. subtilis $\left(1.7 \times 10^{6} \mathrm{CFU} /\right.$ strip $)$ spores using packages containing air or modified atmosphere gas blend $\left(65 \% \mathrm{O}_{2} / 30 \% \mathrm{CO}_{2} / 5 \% \mathrm{~N}_{2}\right)$. Greater than $6 \log _{10}$ reductions were observed after $24 \mathrm{~h}$ of treatment, and these reductions were maintained without additional regrowth at $72 \mathrm{~h}$.

Inactivation of $B$. subtilis spores (D-value $=14 \mathrm{~min}$ ) on polypropylene plates after treatment using atmosphericpressure cold plasma (APCP) generated with helium/oxygen has been shown (Lee et al. 2006). A DC, cold atmosphericpressure air plasma microjet sustained in a quasi-steady gas cavity in water has been shown to successfully inactivate suspended $B$. subtilis spores, with inactivation rate above 97\% in 6 min (Sun et al. 2012).

The sensitivity of various microbes, including $G$. stearothermophilus spores, to a low temperature plasma generated by negative corona discharge was tested (Scholtz et al. 2010). The bacterial spores were inoculated at a low concentration of ca100 $\mathrm{cfu} \mathrm{cm}^{-2}$ and exposed at interelectrode distances of 2, 4, 6, and $10 \mathrm{~mm}$ for $2,4,8,16$, and $32 \mathrm{~min}$. The spore inhibition was observed after a 8-min exposure (the earliest time point). At a high concentration of ca $10^{6} \mathrm{cfu} \mathrm{cm}^{-2}$, no marked inhibition of the spores was observed for exposure times $<30 \mathrm{~min}$. The efficiency of action of the discharge on spores was roughly estimated to be 4- to eightfold less than with vegetative forms. The afterglow of an $\mathrm{N}_{2}-\mathrm{O}_{2}$ corona discharge was used to inactivate G. stearothermophilus (Pointu et al. 2005). In this study, after a treatment time of $30 \mathrm{~min}$, initial counts of $2 \times 10^{4}$ spores were reduced to $6 \times 10^{2}$ 
spores, $2 \times 10^{2}$ spores and $1 \times 10^{2}$ spores upon using pure $\mathrm{N}_{2}, \mathrm{~N}_{2}-\left(2.5 \times 10^{-4}\right) \mathrm{O}_{2}$ gas mixture and $\mathrm{N}_{2}-\left(2.5 \times 10^{-5}\right)$ $\mathrm{O}_{2}$ gas mixture, respectively.

Arc discharge plasma was used to inactivate Fusarium fujikuroi fungal spores in water and on seeds (Kang et al. 2015). Plasma was generated in water by arcing between two electrodes discharged at $10-15 \mathrm{kV}$ DC. Upon treating the fungal spores (total number $2 \times 10^{9}$ ) by arc discharge plasma $(12 \mathrm{kV}, 3 \mathrm{~Hz})$ in water, about $4 \log$ reductions of active spores was observed after a 10-min treatment. On rice seeds, the spores' disinfection rate was proportional to the discharge frequency. On treatment of rice seeds with the arc plasma discharge at $12 \mathrm{~Hz}$ for $30 \mathrm{~min}$, about $80 \%$ disinfection was noted.

The inactivation of $B$. subtilis spores by cold atmospheric plasma (CAP) was investigated using Raman spectroscopy and phase-contrast microscopy (Wang et al. 2016). In this study, $>5 \operatorname{logs}$ of spores deposited on glass surfaces were inactivated by CAP treatment for $3 \mathrm{~min}$, while deposited spores placed inside an impermeable plastic bag were inactivated only-2 $\operatorname{logs}$ in $30 \mathrm{~min}$. On CAP treatment for 1-3 $\mathrm{min},>80 \%$ of spores became non-culturable, and retained calcium dipicolinate (CaDPA) in their core, while $>95 \%$ of spores treated with CAP for 5-10 min lost all CaDPA. CAP treatment for 1-2 min killed $99 \%$ of spores, but these spores still germinated with nutrients or exogenous CaDPA, while spores CAP-treated for $>3$ min that retained CaDPA did not germinate via nutrients or CaDPA. These results suggest that exposure to CAP may result the treated spores either lose CaDPA or can neither initiate nor complete germination with nutrients or CaDPA.

Reineke et al. (2015) investigated the impact of different process gas compositions, argon, argon $+0.135 \%$ vol oxygen, and argon $+0.135 \%$ vol oxygen $+0.2 \%$ vol nitrogen, on the inactivation effect of an atmospheric pressure, nonthermal radio-frequency-driven plasma jet on Bacillus spores, $B$. subtilis PS832 (wild-type) strain and B. atrophaeus. Results showed that the highest inactivation efficiency was observed with treatment by the plasma jet generated using pure argon as carrier gas, a $3.1 \log _{10}$ reduction for $B$. atrophaeus and $2.4 \log _{10}$ for $B$. subtilis after 5 min plasma exposure. And, to reduce total spore count close to statistical detection limit, a 5 min treatment was found sufficient for nearly all gas compositions. In addition, the effect of different process gas compositions on UV sensitive isogenic mutant spore strains of the B. subtilis strain, namely FB122 and PS578, was tested. The strain PS578 showed a higher sensitivity to all plasma carrier gases compared with the wild-type $B$. subtilis strain. Greater than $4 \log _{10}$ were inactivated after 2 min treatment, and the highest sporicidal effect was observed with the gas composition argon $+0.135 \%$ vol oxygen $+0.2 \%$ vol nitrogen. The FB122 spore strain showed a similar inactivation behavior as the PS832 (wild-type), but an up to $0.9 \log _{10}$ higher total inactivation for gas composition with highest UV-C-light emission.

The inactivation efficacy of cold streamers on pathogenic fungi Aspergillus flavus spores, which artificially contaminated pistachio surface, in a sealed package was investigated (Sohbatzadeh et al. 2016). The plasma streamers were generated by an AC high voltage with carrier frequency of $12.5 \mathrm{kHz}$ and exposed for 8-18 min. About 1-log reduction was observed by air plasma treatment at $8-16 \mathrm{~min}$ with a lag phase. A complete removal of fungal contamination was noted after $18 \mathrm{~min}$ of plasma exposure compared with $1.2 \times 10^{5} \mathrm{CFU} / \mathrm{sample}$ in the contaminated control nut samples. Some additional studies on spore inactivation by atmospheric pressure plasmas are given in Table 2.

\section{Synergism with other disinfectants}

The combination of low-temperature plasma (negative corona discharge) and hydrogen peroxide aerosol was shown to exhibit better inactivation effect on several micromycetes spores compared with either negative corona discharge alone or hydrogen peroxide aerosol alone (Cerovsky et al. 2013). In this study, upon exposing (exposition time: $180 \mathrm{~s}$ ) agar plates inoculated with high concentration of spores $\left(100 \mathrm{cfu} \mathrm{cm}^{-2}\right)$ to the combination of negative corona discharge $(2.6 \mathrm{kV}, 500 \mu \mathrm{A})$ and $10 \% \mathrm{H}_{2} \mathrm{O}_{2}$ aerosol, a complete inactivation of spores of Cladosporium sphaerospermum, Byssochlamys nivea, Penicillium corylophilum, Eurotium amstelodami, and Talaromyces striatus was observed. In the tested two other species, Aspergillus and Alternaria, the diameter of inhibition zones increased to $30 \mathrm{~mm}$ only. The better inactivation effect could be due to higher presence of electrons (or negative ions) in negative discharge and following more efficient dissociation of hydrogen peroxide. On the other hand, no inactivation effect was observed following exposure to solely positive corona discharge (Cerovsky et al. 2013).

\section{Activity-responsible plasma species}

Plasma reactive species are reported to be responsible for the sporicidal activity of nonthermal plasmas. Predominant reactive species generated by plasma depend on the type of plasma and conditions under which it is generated. Deng et al. (2006) have showed the profound role of reactive oxygen species, with minor contributions of heat, UV photons, electric field, and charged particles, in the inactivation of $B$. subtilis spores by nonthermal atmospheric plasma. In a study, microwave (MW) plasma was shown to exhibit high sporicidal activity than its radiofrequency (RF) counterpart (Lerouge et al. 2000b). In DBD air plasma-induced spore deactivation, possible roles of ozone and UV emissions generated by DBD in 
dry air and synergistic OH radicals generated by DBD in moist air have been suggested in sterilization process (Eto et al. 2008). UV radiation was projected to be primarily responsible for $B$. subtilis and A. niger inactivation by argon DBD since Ar is chemically inactive (Trompeter et al. 2002). In another study, the role of both UV light and reactive particles generated by cascaded DBD in the destruction of B. subtilis and A. niger spores was highlighted, each of them showing different effectiveness on different types of spores (Heise et al. 2004a). In Bacillus spore inactivation by the flowing afterglow of a DBD in air, highly reactive oxygen species such as $\mathrm{O}, \mathrm{NO}_{2}$ and $\mathrm{OH}$ played a crucial role in the inactivation of microorganisms by damaging outermost membranes (lipids) and proteins (Laroussi and Leipold 2004).

The sporicidal effect of UV in plasmas was reviewed by Yardimci and Setlow (2010), and there is general agreement that the UV spectrum below $300 \mathrm{~nm}$ acts as an efficient lethal agent for spores (Boudam et al. 2006). Several studies concluded the importance of UV in the $~ 260$-nm range in spore inactivation (Boudam et al. 2006; Dobrynin et al. 2010; Feichtinger et al. 2003; Halfmann et al. 2007; von Woedtke et al. 2003). These studies also found that plasma can inactivate spores even in the absence of UV, although more slowly than when the plasma contained UV. On the contrary, a hydrogen MW plasma, which emits vacuum ultraviolet (VUV) radiation (between 115 and $170 \mathrm{~nm}$ ), showed a relatively low sporicidal efficacy despite the high effectiveness of these photons to break chemical bonds (Lerouge et al. 2000b). This could be due to shielding protection of spore DNA by spore coats against VUV, but only minimally against UV at $260 \mathrm{~nm}$ (Yardimci and Setlow 2010). UV photons and reactive (ROS, RNS) as well as metastable species of an atmospheric pressure plasma jet have been shown to exhibit similar sporicidal effects (Reineke et al. 2015).

However, in G. stearothermophilus inactivation using the afterglow of the $\mathrm{N}_{2}-\mathrm{O}_{2}$ corona plasma, singlet-S metastable oxygen atoms $\left[\mathrm{O}\left({ }^{1} \mathrm{~S}\right)\right.$ atoms] were more efficient than UV photons (Pointu et al. 2005). It has been shown that UV photons contributed minimally and charged particles and reactive oxygen species contributed significantly to $B$. $s u b$ tilis spore inactivation by cold atmospheric plasma (CAP) (Wang et al. 2016). In P. digitatum fungal spore inactivation by NEAPP, plasma reactive species, but not UV radiation, were shown to play a major role in inactivation (Iseki et al. 2010). Further systematic investigation on the effectiveness of atomic and excited molecular oxygen species at inactivating the same spores indicated that ground-state atomic oxygen $\mathrm{O}\left({ }^{3} \mathrm{P}_{\mathrm{j}}\right)$ species were crucial in the inactivation by NEAPP, with only minor roles of excited molecular oxygen $\mathrm{O}_{2}\left({ }^{1} \Delta_{\mathrm{g}}\right)$ and $\mathrm{O}_{3}$ (Hashizume et al. 2013). In sterilization of $B$. subtilis spore by DBD plasma, electric field and UV 
associated with the DBD have been shown to have negligible effect on sterilization (Mizuno 2017).

In atmospheric surface micro-discharge (SMD) plasma, as nitrogen and oxygen are the main components of air, the reactive species were mainly composed of reactive oxygen species (ROS), including ozone and hydroxide radicals, and reactive nitrogen species (RNS), including nitrogen oxides. These species might have predominant role in spore inactivation using SMD plasma (Klämpfl et al. 2012). A dominant role of neutral reactive oxygen species in the inactivation of spores was shown by Dobrynin et al. (2010). Under high humidity treatment environment, plasma-activated water (PAW) containing both long-lived and short-lived reactive species seem more likely to contribute to the inactivation of spores. In a plasma-water system, short lived species [such as $\mathrm{OH}, \mathrm{O}_{2}{ }^{-}$and $\mathrm{O}_{2}\left({ }^{1} \Delta_{\mathrm{g}}\right)$ ] were considered to be the most important agents in the inactivation of B. subtilis spores (Sun et al. 2012). In SMD plasma-induced inactivation of G. stearothermophilus, long-lived water-related reactive species (e.g. $\mathrm{H}_{2} \mathrm{O}_{2}$ ) appeared responsible for the sporicidal effect (Jeon et al. 2014). Shockwave generated from arc discharge plasma was believed to contribute substantially to the inactivation of fungal spores associated with rice seeds (Kang et al. 2015).

\section{Spore inactivation mechanism by plasmas}

There are relatively few published studies available that deal with the mechanism of spore inactivation by plasma. In some studies, protective envelopes surrounding the core of spores have been shown to serve as targets for plasmainduced spore inactivation (Deng et al. 2006; Sun et al. 2012; Tseng et al. 2012; Van Bokhorst-van de Veen et al. 2015). These envelops composed of, from innermost to outermost, inner membrane, germ cell wall, cortex, outer membrane, coat and exosporium. Spore coat damage and resultant spore leakage has been shown to be a major cause of plasma inactivation (Tseng et al. 2012). In 'direct exposure', wherein spore sample undergoing treatment is in direct contact with plasma, etching (volatilization) seems to play a major role in the destruction of spores (Lerouge et al. 2000a; Park et al. 2003). The concern of attribution of spore killing to observable damage to spore surfaces, such as the etching of spore surface layers, has been highlighted by Yardimci and Setlow (2010). They interpreted that although etching of surface layers has been observed in certain studies, it is unclear that these morphological changes are causes of spore inactivation. A much less role of the etching mechanism was shown in the case of VUV/UV irradiation (Lerouge et al. 2000b). They concluded that wavelength and intensity of VUV/UV radiation appear to affect its sporicidal effectiveness. It seems, therefore, that the mode of spore inactivation depends on the type of plasma, type of spore and other factors during exposure.

Reactive plasma species that diffuse into spores can cause functional damage to the macromolecules, including membranes and enzymes, leading to inactivation. Boudam et al. (2006) highlighted the induction of local damage (possibly by oxidation to the cytoplasmic membrane, proteins and DNA material) by the diffusion of oxygenated species (e.g. $\mathrm{OH}$ ) through spore material. Damage of spore proteins, especially proteins of the inner membrane, by ROS might be the inactivation mechanism using atmospheric SMD air plasma (Klämpfl et al. 2012). However, the synergistic effect of various SMD air plasma species in inactivation process cannot be ruled out.

Damage and rupture of $B$. subtilis spores after treatment using a microwave induced plasma jet has been shown (Park et al. 2004). The leakage of cytoplasmic contents and a complete rupture of spore membrane in B. subtilis spore inactivation by nonthermal atmospheric-plasma plumes (atmospheric-helium plasma plume and atmospherichelium-oxygen plasma plume) have been reported (Deng et al. 2006).

Several studies pointed towards DNA damage by UV radiation of plasma as the primary cause of spore inactivation (Boudam et al. 2006; Feichtinger et al. 2003; Halfmann et al. 2007; Roth et al. 2010; von Woedtke et al. 2003), although spores can be killed by plasma components other than UV. Damage to macromolecules other than DNA, such as proteins and membranes, may occur in spores by plasma as these structures are sensitive to reactive chemical species in plasma (Mogul et al. 2003; Roth et al. 2010). For the investigation of spore inactivation mechanisms induced by cold atmospheric plasmas, the development of appropriate tools for quantitative identification of plasma species is recommended, in combination with biochemical studies (Klämpfl et al. 2012). In a recent review by Liao et al. (2018), more details related to targets of plasma-induced inactivation in spores have been discussed.

\section{Factors affecting the sporicidal action of plasmas}

\section{Plasma gas composition}

Plasma gas composition influences the efficacy of spore sterilization. In a study, a $\mathrm{O}_{2} / \mathrm{CF}_{4}(88 / 12 \%)$ plasma exhibited higher inactivation efficacy against $B$. subtilis spores than other gases or gas mixtures tested $\left(\mathrm{O}_{2}, \mathrm{O}_{2} / \mathrm{Ar}, \mathrm{O}_{2} / \mathrm{H}_{2}, \mathrm{CO}_{2}\right.$, and $\mathrm{O}_{2} / \mathrm{CF}_{4}$ ) (Lerouge et al. 2000a). In another study, for the inactivation of $B$. subtilis wild-type spores, $\mathrm{N}_{2}$-plasma exhibited the highest inactivation efficiency and a D-value of $0.06 \mathrm{~min}$ among the tested process gasses (dry air, $\mathrm{N}_{2}, \mathrm{O}_{2}$ and $\mathrm{CO}_{2}$ ). The other three tested plasmas showed a similar 
maximum inactivation after a 7-min treatment and D-values between 1.10 and $1.52 \mathrm{~min}$ (Hertwig et al. 2017).

\section{Relative gas humidity}

Relative gas humidity can affect, either positively or negatively, the inactivation efficacy of spores. In a study, an increased A. niger spore mortality from cascaded dielectric barrier discharge (CDBD) in air was observed at a high relative gas humidity of 70\% (Muranyi et al. 2008). In contrast, the same study reported that $B$. subtilis exhibited slightly poorer inactivation at high gas humidity. It has been shown that the sporicidal effect of surface micro-discharge (SMD) plasma depends substantially on humidity within the treatment environment (Jeon et al. 2014). In that study, Almost no sporicidal effect $(<0.5 \log )$ and up to $3.5 \log$ spore $(G$. stearothermophilus) reduction were noted at the humidities of $5.5 \pm 0.5$ and $17.9 \pm 0.6 \mathrm{gm}^{-3}$, respectively.

In a recent study, Hu et al. (2018) demonstrated the influence of water content in working gas (air) of an air-water plasma jet on the inactivation of $P$. digitatum spores on glass slides. The production of $\mathrm{OH}\left(\mathrm{A}^{2} \Sigma^{+}-\mathrm{X}^{2} \Pi_{\mathrm{i}}\right)$ enhanced with the increase of water content (in the range of $2.53-9.58 \mathrm{mg} \mathrm{L}^{-1}$, depending on gas/water mixture ratio), whereas $\mathrm{O}\left(3 \mathrm{p}^{5} \mathrm{P}-3 \mathrm{~s}^{5} \mathrm{~S}\right)$ level declined with higher water content. A proportional relationship was observed between the inactivation efficiency and the water content of the plasma. A maximum inactivation efficacy of $93 \%$ was observed at a water content of $9.58 \mathrm{mg} \mathrm{L}^{-1}$ and at an applied voltage of $-6.75 \mathrm{kV}$.

\section{Spore coat structure and pigmentation}

Spores lacking the inner, or the outer coat and spores deficient in spore encasement are significantly more sensitive to all plasma treatments. The spore coat is a permeability barrier and it restricts the access of large molecules such as enzymes. The absorption of UV-C and vacuum-UV photons by the outer and inner B. subtilis spore coat, and thereby protecting the spore against radiation-induced damage, has been shown (Fiebrandt et al. 2017). In addition, spores lacking CotA-dependent pigmentation are sensitive to plasma discharges containing a high degree of environmentally relevant UV radiation (Raguse et al. 2016).

\section{Resistance of spores to plasmas}

Several factors, including multilayer morphology, have been shown to be involved in the extreme resistance of Bacillus spores towards various environmental stresses (Hertwig et al. 2017). In this study, Alpha/beta-type small, acid-soluble proteins (SASP), which protect spores' DNA against different kinds of damage (caused by wet and dry heat, $\gamma$-irradiation, various chemicals and UV photons), have been shown to contribute to the spores' cold atmospheric pressure plasma (CAPP) resistance.

\section{Surface density}

Surface density of spores on carriers was shown to be an important parameter influencing plasma-induced spore inactivation. In a study, less densely distributed $B$. subtilis spores exhibited higher rate of destruction by $\mathrm{CO}_{2}$ plasma (Hury et al. 1998). On the contrary, Purevdorj et al. (2001) showed that the initial surface density of Bacillus spores did not affect their survival during the plasma treatment.

\section{Conclusions and outlook}

From these studies, it can be concluded that both low and atmospheric pressure plasmas have potential sporicidal activity. Microwave discharges at low pressures may be more suitable for spore inactivation. Under atmospheric pressure conditions, dielectric barrier discharges and radio-frequency plasmas have been majorly used for spore inactivation. Even with one type of spores, different types of plasmas exhibit varied levels of sporicidal effect depending on several influential treatment parameters. Also, the mechanism of spore inactivation seems to be dependent on the type of plasma source. However, more systematic studies are needed for a detailed understanding of the mechanism of plasma-induced spore inactivation. Both cold plasma factors and microbial factors influence the inactivation of spores. Possible synergistic effects between cold plasma and other sporicidal agents need to be explored systematically since this strategy can address the concern of the development of resistance to sporicidal agents or can be beneficial in the inactivation of highly resistant spores.

Acknowledgements The authors gratefully acknowledge financial support from the Ottogi Foundation, Korea.

Funding This study was funded by the Ottogi Foundation, Korea (Grant No. 2016-0066).

\section{Compliance with ethical standards}

Conflict of interest The authors declare that they have no competing interests.

\section{References}

Akhtara S, Paredes-Sabja D, Antonio Torres J, Sarker MR (2009) Strategy to inactivate Clostridium perfringens spores in meat products. Food Microbiol 26:272-277. https://doi.org/10.1016/j. fm.2008.12.011 
Akitsu T, Ohkawa H, Tsuji M, Kimura H, Kogoma M (2005) Plasma sterilization using glow discharge at atmospheric pressure. Surf Coat Technol 193:29-34. https://doi.org/10.1016/j.surfc oat.2004.07.042

Asenjo-Castillo J, Vargas-Blanco I (2016) Emission spectroscopy of an atmospheric pressure plasma. Revista Tecnología en Marcha 29:47-58. https://doi.org/10.18845/tm.v29i6.2901

Ashman LE, Menashi WP (1972) Treatment of surface with low-pressure plasmas. U.S. Patent No. 3,701,628

Bithell RM (1982) Package and sterilizing process for same. U.S. Patent No. 4,321,232

Boucher RMG (1980) Seeded gas plasma sterilization method. US Patent No 4:207,268

Boucher RMG (1985) State of the art in gas plasma sterilization. Med Device Diagn Ind 7:51-56

Boudam MK, Moisan M, Saoudi B, Popovici C, Gherardi N, Massines $\mathrm{F}$ (2006) Bacterial spore inactivation by atmospheric-pressure plasmas in the presence or absence of UV photons as obtained with the same gas mixture. J Phys D Appl Phys 39:3494-3507. https://doi.org/10.1088/0022-3727/39/16/S07

Cerovsky M, Khun J, Rusova K, Scholtz V, Souskova H (2013) Inactivation of possible micromycete food contaminants using the low-temperature plasma and hydrogen peroxide. Plasma Phys Rep 39:763-767. https://doi.org/10.1134/S1063780X1309002X

Deilmann M, Halfmann H, Bibinov N, Wunderlich J, Awakowicz P (2008) Low-pressure microwave plasma sterilization of polyethylene terephthalate bottles. J Food Protect 71:2119-2123. https:// doi.org/10.4315/0362-028X-71.10.2119

Deng X, Shi J, Kong MG (2006) Physical mechanisms of inactivation of Bacillus subtilis spores using cold atmospheric plasmas. IEEE T Plasma Sci 34:1310-1316. https://doi.org/10.1109/ TPS.2006.877739

Dobrynin D, Fridman G, Mukhin YV, Wynosky-Dolfi MA, Rieger J, Rest RF, Gutsol AF, Fridman A (2010) Cold plasma inactivation of Bacillus cereus and Bacillus anthracis (anthrax) spores. IEEE T Plasma Sci 38:1878-1884. https://doi.org/10.1109/ TPS.2010.2041938

Eissa ME, Naby MAE, Beshir MM (2014) Bacterial vs. fungal spore resistance to peroxygen biocide on inanimate surfaces. Bull Fac Pharm Cairo Univ 52:219-224. https://doi.org/10.1016/j.bfopc u.2014.06.003

Eto H, Ono Y, Ogino A, Nagatsu M (2008) Low-temperature sterilization of wrapped materials using flexible sheet-type dielectric barrier discharge. Appl Phys Lett 93:221502. https://doi. org/10.1063/1.3039808

Feichtinger J, Schulz A, Walker M, Schumacher U (2003) Sterilization with low-pressure microwave plasmas. Surf Coat Technol 174175:564-569. https://doi.org/10.1016/S0257-8972(03)00404-3

Fiebrandt M, Lackmann JW, Raguse M, Moeller R, Awakowicz P, Stapelmann K (2017) VUV absorption spectroscopy of bacterial spores and DNA components. Plasma Phys Control Fusion 59:014010. https://doi.org/10.1088/0741-3335/59/1/014010

Fridman A, Kennedy L (2004) Plasma physics and engineering. Taylor \& Francis, New York

Friedrich LM, Goodrich-Schneider R, Parish ME, Danyluk MD (2009) Mitigation of Alicyclobacillus spp. spores on food contact surfaces with aqueous chlorine dioxide and hypochlorite. Food Microbiol 26:936-941. https://doi.org/10.1016/j.fm.2009.06.011

Gayán E, Álvarez I, Condón S (2013) Inactivation of bacterial spores by UV-C light. Innov Food Sci Emerg 19:140-145. https://doi. org/10.1016/j.ifset.2013.04.007

Gould GW (1983) Mechanisms of resistance and dormancy. In: Hurst A, Gould GW (eds) The bacterial spore. Academic Press, London, pp 173-209

Halfmann H, Denis B, Bibinov N, Wunderlich J, Awakowicz P (2007) Identification of the most efficient VUV/UV radiation for plasma based inactivation of Bacillus atrophaeus spores. J Phys D Appl Phys 40:5907-5911. https://doi. org/10.1088/0022-3727/40/19/019

Hashizume H, Ohta T, Fengdong J, Takeda K, Ishikawa K, Hori M, Ito M (2013) Inactivation effects of neutral reactive-oxygen species on Penicillium digitatum spores using non-equilibrium atmospheric-pressure oxygen radical source. Appl Phys Lett 103:153708. https://doi.org/10.1063/1.4824892

Heise M, Neff W, Franken O, Muranyi P, Wunderlich J (2004a) Sterilization of polymer foils with dielectric barrier discharges at atmospheric pressure. Plasmas Polym 9:23-33. https://doi.org/10.1023/ B:PAPO.0000039814.70172.c0

Heise M, Lierfeld T, Franken O, Neff W (2004b) Single filament charge transfer and UV-emission properties of a cascaded dielectric barrier discharge (CDBD) set-up. Plasma Sources Sci T 13:351-358. https://doi.org/10.1088/0963-0252/13/2/023

Hertwig C, Reineke K, Ehlbeck J, Knorr D, Schlüter O (2015) Decontamination of whole black pepper using different cold atmospheric pressure plasma applications. Food Control 55:221-229. https:// doi.org/10.1016/j.foodcont.2015.03.003

Hertwig C, Reineke K, Rauh C, Schlüter O (2017) Factors involved in Bacillus spore's resistance to cold atmospheric pressure plasma. Innov Food Sci Emerg 43:173-181. https://doi.org/10.1016/j.ifset .2017 .07 .031

Hong YF, Kang JG, Lee HY, Uhm HS, Moon E, Park YH (2009) Sterilization effect of atmospheric plasma on Escherichia coli and Bacillus subtilis endospores. Lett Appl Microbiol 48:(2009) 33-37. https://doi.org/10.1111/j.1472-765X.2008.02480.x

$\mathrm{Hu}$ Y, Zhu W, Liu K, Han L, Zheng Z, Hu H (2018) Influence of water content on the inactivation of $P$. digitatum spores using an air-water plasma jet. Plasma Sci Technol 20:044011. https://doi. org/10.1088/2058-6272/aaa8da

Huang Y (2011) Non-thermal plasma inactivation of Bacillus amyloliquefaciens spores. Master's Thesis, University of Tennessee, 2011

Hugo WB, Russell AD (1998) Chemical disinfectants, antiseptics and preservatives. In: Denyer SP, Hodges N, Gorman SP (eds) Hugo and Russell's pharmaceutical microbiology, 6th edn. Blackwell Science Ltd, Oxford, pp 201-228

Humphreys PN (2011) Testing standards for sporicides. J Hosp Infect 77:193-198. https://doi.org/10.1016/j.jhin.2010.08.011

Hury S, Vidal DR, Desor F, Pelletier J, Lagarde T (1998) A parametric study of the destruction efficiency of Bacillus spores in low pressure oxygen-based plasmas. Lett Appl Microbiol 26:417-421

Iseki S, Ohta T, Aomatsu A, Ito M, Kano H, Higashijima Y, Hori M (2010) Rapid inactivation of Penicillium digitatum spores using high-density nonequilibrium atmospheric pressure plasma. Appl Phys Lett 96:153704. https://doi.org/10.1063/1.3399265

Jeon J, Klaempfl TG, Zimmermann JL, Morfill GE, Shimizu T (2014) Sporicidal properties from surface micro-discharge plasma under different plasma conditions at different humidities. New J Phys 16:103007. https://doi.org/10.1088/1367-2630/16/10/103007

Kang MH, Pengkit A, Choi K, Jeon SS, Choi HW, Shin DB, Choi EH, Uhm HS, Park G (2015) Differential inactivation of fungal spores in water and on seeds by ozone and arc discharge plasma. PLoS ONE 10:e0139263. https://doi.org/10.1371/journal.pone.0139263

Keener KM, Jensen JL, Valdramidis VP, Byrne E, Connolly J, Mosnier JP, Cullen PJ (2012) Decontamination of Bacillus subtilis spores in a sealed package using a non-thermal plasma system. In: Machala Z, Hensel K, Akishev Y (eds) Plasma for bio-decontamination, medicine and food security. NATO science for peace and security series A: chemistry and biology, Springer, Dordrecht, pp 445-455

Kim JE, Lee DU, Min SC (2014) Microbial decontamination of red pepper powder by cold plasma. Food Microbiol 38:128-136. https ://doi.org/10.1016/j.fm.2013.08.019 
Kim JE, Oh YJ, Won MY, Lee KS, Min SC (2017) Microbial decontamination of onion powder using microwave-powered cold plasma treatments. Food Microbiol 62:112-123. https://doi. org/10.1016/j.fm.2016.10.006

Klämpfl TG, Isbary G, Shimizu T, Li YF, Zimmermann JL, Stolz W, Schlegel J, Morfill GE, Schmidt HU (2012) Cold atmospheric air plasma sterilization against spores and other microorganisms of clinical interest. Appl Environ Microb 78:5077-5082. https ://doi.org/10.1128/AEM.00583-12

Laroussi M, Leipold F (2004) Evaluation of the roles of reactive species, heat, and UV radiation in the inactivation of bacterial cells by air plasmas at atmospheric pressure. Int J Mass Spectrom 233:81-86. https://doi.org/10.1016/j.ijms.2003.11.016

Laroussi M, Kong MG, Morfill G, Stolz W (2012) Plasma medicine. Cambridge University Press, Cambridge

Lee K, Paek KH, Ju WT, Lee Y (2006) Sterilization of bacteria, yeast, and bacterial endospores by atmospheric-pressure cold plasma using helium and oxygen. J Microbiol 44:269-275

Leggett MJ, McDonnell G, Denyer SP, Setlow P, Maillard JY (2012) Bacterial spore structures and their protective role in biocide resistance. J Appl Microbiol 113:485-498. https://doi.org/10.1 111/j.1365-2672.2012.05336.x

Lerouge S, Wertheimer MR, Marchand R, Tabrizian M, Yahia LH (2000a) Effect of gas composition on spore mortality and etching during low-pressure plasma sterilization. J Biomed Mater Res 51:128-135. https://doi.org/10.1002/(SICI)10974636(200007)51:1\%3C128::AID-JBM17\%3E3.0.CO;2-\%23

Lerouge S, Fozza AC, Wertheimer MR, Marchand R, Yahia LH (2000b) Sterilization by low-pressure plasma: the role of vacuum-ultraviolet radiation. Plasmas Polym 5:31-46. https://doi. org/10.1023/A:1009504209276

Liao X, Muhammad AI, Chen S, Hu Y, Ye X, Liu D, Ding T (2018) Bacterial spore inactivation induced by cold plasma. Crit Rev Food Sci Nutr. https://doi.org/10.1080/10408398.2018.1460797

Matsubara H, Goto K, Matsumura T, Mochida K, Iwaki M, Niwa M, Yamasato K (2002) Alicyclobacillus acidophilus sp. nov., a novel thermo-acidophilic, $\omega$-alicyclic fatty acid containing bacterium from acidic beverages. Int J Syst Evol Microbiol 52:1681-1685. https://doi.org/10.1099/00207713-52-5-1681

McClane BA (2001) Clostridium perfringens. In: Doyle MP, Montville TJ (eds) Food microbiology: fundamentals and frontiers, 2nd edn. ASM Press, Washington, DC, pp 351-372

Menashi WP (1968) Treatment of surfaces. US Patent 3:383,163

Merle J, Montville TJ (2014) Alicyclobacillus acidoterrestris: the organism, the challenge, potential interventions. J Food Process Preserv 38:153-158. https://doi.org/10.111 $1 /$ j.1745-4549.2012.00758.x

Mizuno A (2017) Destruction of biological particles using nonthermal plasma. J Clin Biochem Nutr 60:12-24. https://doi. org/10.3164/jcbn.16-64

Mogul R, Bolapos;shakov AA, Chan SL, Stevens RM, Khare BN, Meyyappan M, Trent JD (2003) Impact of low-temperature plasmas on Deinococcus radiodurans and biomolecules. Biotechnol Progr 19:776-783. https://doi.org/10.1021/bp025665e

Moreau S, Moisan M, Tabrizian M, Barbeau J, Pelletier J, Ricard A, Yahia LH (2000) Using the flowing afterglow of a plasma to inactivate Bacillus subtilis spores: Influence of the operating conditions. J Appl Phys 88:1166-1174. https://doi. org/10.1063/1.373792

Muranyi P, Wunderlich J, Heise M (2008) Influence of relative gas humidity on the inactivation efficiency of a low temperature gas plasma. J Appl Microbiol 104:1659-1666. https://doi.org/10.1 111/j.1365-2672.2007.03691.x

Nehra V, Kumar A, Dwivedi HK (2008) Atmospheric non-thermal plasma sources. Int J Eng 2:53-68
Nicholson WL, Galeano B (2003) UV resistance of Bacillus anthracis spores revisited: validation of Bacillus subtilis spores as UV surrogates for spores of B. anthracis Sterne. Appl Environ Microb 69:1327-1330. https://doi.org/10.1128/ AEM.69.2.1327-1330.2003

Nicholson WL, Munakata N, Horneck G, Melosh HJ, Setlow P (2000) Resistance of Bacillus endospores to extreme terrestrial and extraterrestrial environments. Microbiol Mol Biol R 64:548-572

Park BJ, Lee DH, Park JC, Lee IS, Lee KY, Hyun SO, Chun MS, Chung KH (2003) Sterilization using a microwave-induced argon plasma system at atmospheric pressure. Phys Plasmas 10:45394544. https://doi.org/10.1063/1.1613655

Park JC, Park BJ, Han DW, Lee DH, Lee IS, Hyun SO, Chun MS, Chung KH, Aihara M, Takatori K (2004) Fungal sterilization using microwave-induced argon plasma at atmospheric pressure. J Microbiol Biotechnol 14:188-192

Patil S, Moiseev T, Misra NN, Cullen PJ, Mosnier JP, Keener KM, Bourke P (2014) Influence of high voltage atmospheric cold plasma process parameters and role of relative humidity on inactivation of Bacillus atrophaeus spores inside a sealed package. J Hosp Infect 88:162-169. https://doi.org/10.1016/j. jhin.2014.08.009

Pointu AM, Ricard A, Dodet B, Odic E, Larbre J, Ganciu M (2005) Production of active species in $\mathrm{N}_{2}-\mathrm{O}_{2}$ flowing post-discharges at atmospheric pressure for sterilization. J Phys D Appl Phys 38:1905-1909. https://doi.org/10.1088/0022-3727/38/12/009

Purevdorj D, Igura N, Shimoda M, Ariyada O, Hayakawa I (2001) Kinetics of inactivation of Bacillus spores using low temperature argon plasma at different microwave power densities. Acta Biotechnol 21(4):333-342. https://doi.org/10.1002/1521-3846(20011 1) $21: 4 \% 3 \mathrm{C} 333:$ :AID-ABIO333\%3E3.0.CO;2-6

Raguse M, Fiebrandt M, Denis B, Stapelmann K, Eichenberger P, Driks A, Eaton P, Awakowicz P, Moeller R (2016) Understanding of the importance of the spore coat structure and pigmentation in the Bacillus subtilis spore resistance to low-pressure plasma sterilization. J Phys D Appl Phys 49:285401. https://doi. org/10.1088/0022-3727/49/28/285401

Ratner BD, Chilkoti A, Lopez GP (1990) Plasma deposition and treatment for biomaterial applications. In: D'Agostino R (ed) Plasma deposition, treatment and etching of polymers. Academic Press, New York, pp 463-516

Reineke K, Langer K, Hertwig C, Ehlbeck J, Schluter O (2015) The impact of different process gas compositions on the inactivation effect of an atmospheric pressure plasma jet on Bacillus spores. Innov Food Sci Emerg 30:112-118. https://doi.org/10.1016/j.ifset .2015.03.019

Roth S, Feichtinger J, Hertel C (2010) Characterization of Bacillus subtilis spore inactivation in low-pressure, low-temperature gas plasma sterilization processes. J Appl Microbiol 108:521-531. https://doi.org/10.1111/j.1365-2672.2009.04453.x

Russell AD (1990) Bacterial spores and chemical sporicidal agents. Clin Microbiol Rev 3:99-119

Sagong HG, Cheon HL, Kim SO, Lee SY, Park KH, Chung MS, Choi YJ, Kang DH (2013) Combined effects of ultrasound and surfactants to reduce Bacillus cereus spores on lettuce and carrots. Int J Food Microbiol 160:367-372. https://doi.org/10.1016/j.ijfoo dmicro.2012.10.014

Schnabel U, Niquet R, Andrasch M, Jakobs M, Schlüter O, Katroschan KU, Weltmann KD, Ehlbeck J (2016) Broccoli: antimicrobial efficacy and influences to sensory and storage properties by microwave plasma-processed air treatment. Plasma Med 6:375-388. https://doi.org/10.1615/PlasmaMed.2017019033

Schneider J, Baumgärtner KM, Feichtinger J, Krüger J, Muranyi P, Schulz A, Walker M, Wunderlich J, Schumacher U (2005) Investigation of the practicability of low-pressure microwave plasmas in the sterilisation of food packaging materials at industrial level. 
Surf Coat Technol 200:962-966. https://doi.org/10.1016/j.surfc oat.2005.01.114

Scholtz V, Julak J, Kriha V (2010) The microbicidal effect of lowtemperature plasma generated by corona discharge: comparison of various microorganisms on an agar surface or in aqueous suspension. Plasma Process Polym 7:237-243. https://doi.org/10.1002/ ppap. 200900072

Scholtz V, Pazlarova J, Souskova H, Khun J, Julak J (2015) Nonthermal plasma - a tool for decontamination and disinfection. Biotechnol Adv 33:1108-1119. https://doi.org/10.1016/j.biotechadv .2015.01.002

Setlow P (2006) Spores of Bacillus subtilis: their resistance to and killing by radiation, heat and chemicals. J Appl Microbiol 101:514525. https://doi.org/10.1111/j.1365-2672.2005.02736.x

Setlow P (2013) Resistance of bacterial spores to chemical agents. In: Fraise AP, Maillard JY, Sattar SA (eds) Russell, Hugo \& Ayliffe's: principles and practice of disinfection, preservation \& sterilization. Wiley-Blackwell, Oxford, pp 121-130

Sharma A, Pruden A, Yu Z, Collins GJ (2005) Bacterial inactivation in open air by the afterglow plume emitted from a grounded hollow slot electrode. Environ Sci Technol 39:339-344. https://doi. org/10.1021/es049452s

Silva MP, Pereira CA, Junqueira JC, Jorge AOC (2013) Methods of destroying bacterial spores. In: Méndez-Vilas A (ed) Microbial pathogens and strategies for combating them: science, technology and education, FORMATEX, Badajoz, pp 490-496

Singh MK, Ogino A, Nagatsu M (2009) Sterilization efficiency of inactivation factors in a microwave plasma device. J Plasma Fusion Res Ser 8:560-563

Sohbatzadeh F, Mirzanejhad S, Shokri H, Nikpour M (2016) Inactivation of Aspergillus flavus spores in a sealed package by cold plasma streamers. J Theor Appl Phys 10:99-106. https://doi. org/10.1007/s40094-016-0206-Z

Songer JG (1996) Clostridial enteric diseases of domestic animals. Clin Microbiol Rev 9:216-234

Stapelmann K, Fiebrandt M, Raguse M, Awakowicz P, Reitz G, Moeller R (2013) Utilization of low-pressure plasma to inactivate bacterial spores on stainless steel screws. Astrobiology 13:597-606. https://doi.org/10.1089/ast.2012.0949

Sun P, Wu H, Bai N, Zhou H, Wang R, Feng H, Zhu W, Zhang J, Fang J (2012) Inactivation of Bacillus subtilis spores in water by a direct-current, cold atmospheric-pressure air plasma microjet. Plasma Process Polym 9:157-164. https://doi.org/10.1002/ ppap. 201100041

Tendero C, Tixier C, Tristant P, Desmaison J, Leprince P (2006) Atmospheric pressure plasmas: a review. Spectrochim Acta B 61:2-30. https://doi.org/10.1016/j.sab.2005.10.003
Thiyagarajan M (2004) A Characteristic study of the atmospheric pressure nonthermal resistive barrier plasma discharge for biological decontamination. Master's Thesis, University of Tennessee, 2004

Trompeter FJ, Neff WJ, Franken O, Heise M, Neiger M, Liu SH, Pietsch GJ, Saveljew AB (2002) Reduction of Bacillus subtilis and Aspergillus niger spores using nonthermal atmospheric gas discharges. IEEE T Plasma Sci 30:1416-1423. https://doi. org/10.1109/TPS.2002.804182

Tseng S, Abramzon N, Jackson JO, Lin WJ (2012) Gas discharge plasmas are effective in inactivating Bacillus and Clostridium spores. Appl Microbiol Biotechnol 93:2563-2570. https://doi. org/10.1007/s00253-011-3661-0

Uemura K, Takahashi C, Kobayashi I (2010) Inactivation of Bacillus subtilis spores in soybean milk by radio-frequency flash heating. J Food Eng 100:622-626. https://doi.org/10.1016/j.jfood eng.2010.05.010

Van Bokhorst-van de Veen H, Xie H, Esveld E, Abee T, Mastwijk $\mathrm{H}$, Groot MN (2015) Inactivation of chemical and heat-resistant spores of Bacillus and Geobacillus by nitrogen cold atmospheric plasma evokes distinct changes in morphology and integrity of spores. Food microbiol 45:26-33. https://doi.org/10.1016/j. fm.2014.03.018

von Woedtke T, Jülich WD, Thal S, Diederich M, Stieber M, Kindel E (2003) Antimicrobial efficacy and potential application of a newly developed plasma-based ultraviolet irradiation facility. J Hosp Infect 55:204-211. https://doi.org/10.1016/S0195-6701(03)00290 $-1$

von Woedtke T, Haese K, Heinze J, Oloff C, Stieber M, Julich WD (2004) Sporicidal efficacy of hydrogen peroxide aerosol. Pharmazie 59:207-211

Waites WM (1985) Inactivation of spores with chemical agents. In: Dring GJ, Ellar DJ, Gould GW (eds) Fundamental and applied aspects of bacterial spores. Academic Press Inc., New York, pp 383-396

Wang S, Doona CJ, Setlow P, Li YQ (2016) Use of Raman spectroscopy and phase-contrast microscopy to characterize cold atmospheric plasma inactivation of individual bacterial spores. Appl Environ Microbiol 82:5775-5784. https://doi.org/10.1128/ AEM.01669-16

Yardimci O, Setlow P (2010) Plasma sterilization: opportunities and microbial assessment strategies in medical device manufacturing. IEEE T Plasma Sci 38:973-981. https://doi.org/10.1109/ TPS.2010.2041674 